\title{
Vicissitudes da indústria cultural em tempos de globalização*
}

\author{
Alex Sander da Silval \\ Universidade do Extremo Sul Catarinense
}

Neste artigo se examinam algumas conseqüências, para o campo da educação, do modelo de conformação cultural adotado pela indústria cultural sob o signo da globalização. Na raiz do problema da educação, encontra-se a intricada questão do papel que desempenha a indústria cultural globalizada. Aqui nos interessa apontar para três elementos fortes que se intercalam entre si: a) o poder da produção e do consumo de bens culturais imposto pela indústria cultural; b) o evidente processo de dissolução da subjetividade como marca registrada de uma sociedade em que os indivíduos são absorvidos por ela mesma, ou seja, pela massificação cultural; c) uma educação danificada que se alinha, principalmente, aos aspectos que dificultam a resistência crítica. A intenção aqui é anotar como os mecanismos da indústria cultural contribuem para o modelo de conformação cultural atual. Nesse sentido, busca-se demarcar a necessidade de resistir aos ditames dessa conformação, de modo particular, pelos processos educacionais.
This paper examines some consequences for the field of education, cultural model of conformation adopted by the culture industry, under the banner of globalization. At the root of the problem of education, we find the intricate question of the role played by the global culture industry. Interests us here to point out to three strong elements that are interspersed between them: a) the power production and consumption of cultural goods imposed by the culture industry; b) the obvious process of dissolution of subjectivity as the trademark of a society in which individuals are absorbed by itself, or by mass culture, c) an education damaged that aligns, especially those aspects that hinder the critical resistance. The intent here is to note how the mechanisms of cultural industries contribute to the current cultural model conformation. In this sense, it seeks to demarcate the need to resist the dictates of that conformation, in particular, the educational processes.
Palavras-chave: Indústria cultural Subjetividade - Educação - Massificação cultural
Keywords: Cultural industry - Subjectivity -Education - Cultural massification

\footnotetext{
* Vicissitudes of the cultural industry in times of globalization

${ }^{1}$ Endereço para correspondências: Programa de Pós-Graduação em Educação, Universidade do Extremo Sul Catarinense, Avenida Universitária, 1105, Bairro Universitário, Criciúma, SC, 88806-000 (alex17sanders@yahoo.com.br).
} 


\section{Introdução}

chamada cultura pop fornece, no cenário atual, a impressão de que a
subjetividade está solidificada em algo que não tem mais volta, isto é, na globalização econômica e cultural do capitalismo. O que, nos dias de hoje, se realiza como uma aparente robusteza da cultura mundial, ou como o domínio global dos mercados, nada mais é do que a somatória de rudeza e insensibilidade imposta aos indivíduos pela globalização mercadológica.

Essa conclusão, apesar de apressada, aponta para a imensa dificuldade que encontramos quando vamos tratar sobre o tema da indústria cultural em nossos dias. Aqui nos interessa apontar para três elementos fortes que se intercalam em nosso contexto: a) a produção e o consumo de bens culturais impostos pela indústria cultural globalizada, na perspectiva de Horkheimer e Adorno², b) o evidente processo de dissolução da subjetividade, como marca de uma sociedade em que os indivíduos acabam sendo absorvidos por ela mesma (massificação cultural); c) uma educação danificada que se alinha, principalmente, aos aspectos da globalização cultural hegemônica, que tem dificultado a resistência crítica.

A intenção aqui é anotar como os mecanismos da indústria cultural contribuem para o modelo de conformação cultural atual. Nesse sentido, busca-se demarcar a necessidade de resistir aos ditames dessa conformação, de modo particular, pelos processos educacionais.

\section{Vicissitudes da indústria cultural}

O conceito de indústria cultural aparece de forma recorrente quando Adorno e Horkheimer, no texto A Indústria Cultural: o esclarecimento como mistificação das massas, falavam do domínio mercantil da cultura de massa, isto é, no sentido de fundamentar a produção e difusão cultural altamente planejada. Para eles, a indústria cultural promove a dominação técnica na produção e difusão de bens culturais. Nesse sentido, ela opera fazendo com que o valor de uso desses bens seja substituído pelo valor de troca, permitindo que os critérios econômicos imperem e orientem de maneira incondicional a produção industrial da cultura.

\footnotetext{
${ }^{2}$ Max Horkheimer (1895-1973) e Theodor W. Adorno (1903-69), estão entre os principais expoentes do que se convencionou chamar como "Teoria Crítica" da Escola de Frankfurt, cuja as obras tem influenciado enorme e significativamente a teoria social contemporânea. Ver detalhes em: $A$ Escola de Frankfurt: história, desenvolvimento teórico, significação política, de Rolf Wiggershaus (2002); A teoria crítica ontem e hoje, de Bárbara Freitag (1988); Escola de Frankfurt: luzes e sombras do iluminismo (MATOS, 1993); Adorno: o poder educativo do pensamento crítico (ZUIN et al., 2001).
} 
Se por um lado, as pretensões da indústria cultural giram em torno de oferecer bens culturais que possam ser facilmente comercializados, acessíveis ao consumo do grande público, por outro, tais produtos se tornam fontes de orientação da manutenção do poder dominante do mercado capitalista insaciável. Nesse contexto, pode-se observar que o poder que a classe economicamente mais forte exerce sobre o restante da sociedade se dá de forma racionalizada pela própria indústria cultural. É por ela que a cultura industrializada se transforma em racionalidade dominadora.

Assim, as mercadorias culturais previamente pensadas servem para integrar a sociedade e seus indivíduos ao modo de vida vigente, invadindo sua própria vida cotidiana. O que rege a sociedade sob o domínio do capitalismo é a lei do mercado, e, com isso, quem consegue acompanhar esse ritmo e essa ideologia de vida tenta sobreviver; aquele que não consegue fica à mercê dos "dirigentes do poder do monopólio".

Sob o poder do monopólio, toda cultura de massa é idêntica, o seu esqueleto, a ossatura conceitual fabricada por aquele, começa a se delinear. Os dirigentes não estão mais sequer interessados em encobri-lo, seu poder se fortalece quanto mais brutalmente ele se confessa de público. O cinema e o rádio não precisam mais se apresentar como arte. A verdade é que não passam de um negócio, eles [os dirigentes] a utilizam como uma ideologia destinada a legitimar o lixo que propositalmente produzem. Eles [o cinema e a arte] se definem a si mesmos como indústrias, e as cifras publicadas dos rendimentos de seus diretores gerais suprimem toda a dúvida quanto à necessidade social de seus produtos. (ADORNO \& HORKHEIMER, 1985; p. 114).

Os produtos oferecidos pela cultura industrializada são fontes de orientação em que se experimentam situações análogas às da vida real. $\mathrm{O}$ mundo "pintado" pela indústria da cultura é simplesmente ilusório, utilizado para orientar e alienar a consciência dos indivíduos. O que se estabelece é um sistema em que os indivíduos são induzidos a acreditar que suas necessidades dependem da indústria cultural.

Há uma intenção deliberada nos mecanismos da indústria cultural de reprodução dos objetos da realidade. Quanto maior o grau de perfeição nessa reprodução, mais facilmente se cria a ilusão de que o mundo exterior é um prolongamento do que se vê no cinema, nas novelas. Até mesmo nos romances literários, denominados de "literatura de massa", por exemplo, se expressam as artimanhas da ideologia dominante. 
O processo consiste em adestrar o espectador, para que o mesmo se entregue ao que está lendo ou assistindo, até o ponto de identificar-se com a realidade. O entretenimento substitui as vontades próprias do indivíduo, que se vê absorvido pelos apelos dos produtos culturais. Como mencionam Adorno e Horkheimer (1985, p. 134), "a fusão atual da cultura e do entretenimento não se realiza apenas como depravação da cultura, mas igualmente como espiritualização forçada da diversão".

Segundo Schweppenhäuser (1999; p. 48), “... a função da indústria cultural consistiria na reduplicação do mundo existente que imporia aos produtos culturais fabricados industrialmente seu conteúdo e sua forma". Nesse sentido, o universo social, além de configurar-se como um universo de coisas, constituiria um espaço hermeticamente fechado. E, assim, todas as tentativas de se livrar desse engodo estão condenadas ao fracasso. Compreender as relações entre a sociedade vigente e a indústria cultural demanda, na atualidade, considerar as interações dos meios de comunicação de massa com os aspectos de perpetuação da ideologia dominante.

Com efeito, os frankfurtianos criticam a concepção de cultura de massa, e sentem asco em pensar na possibilidade de que todos os produtos artísticos são originários de condições respaldadas na debilidade de milhões de excluídos. Aqui cabe ressaltar que a padronização sofisticada da produção da cultura é ela mesma fruto da pretensão da racionalidade esclarecida. Na relação de troca, na comercialização como mercadoria, a cultura transforma-se em coisa e não consegue realizar o distanciamento da realidade que a produziu.

Nesse sentido, é preciso ir além de uma análise direta dos artefatos da cultura em termos de mercadoria. É este, sem dúvida, o ponto em que a análise da indústria cultural retorna ao contexto mais amplo em que está submetida, isto é, a racionalização sofisticada da dominação. A maquinaria da indústria cultural é o prolongamento da manipulação ideológica sob as formas de "distração" ou "entretenimento".

As diferenças entre as companhias cinematográficas e as marcas de carros ilustram bem essa condição, elas fazem apenas uma distinção ilusória dos seus produtos. Conforme Adorno e Horkheimer (1985, p. 116), "o esquematismo do procedimento mostra-se no fato de que os produtos mecanicamente diferenciados acabam por se revelar sempre como a mesma coisa". A difusão e o consumo dos bens simbólicos ou materiais acionados pela indústria cultural não deixam de ser irônicos e, por isso, a liberação prometida pelo entretenimento decreta apenas a falência da integração irracional da coletividade.

Isso aponta para a crítica ao capitalismo industrial, que avança na dominação da cultura, provocando a ruína da própria condição da subjetividade humana. Por meio da indústria cultural, a violência da sociedade industrial instalou-se na vida social de uma forma muito ampla. Cada um de seus produtos 
pertence a uma enorme "maquinaria econômica" cuja tarefa é empreender o domínio em todo âmbito da vida dos indivíduos, tanto no trabalho quanto no descanso, em que este não se diferencia em nada ao primeiro.

O que tem lugar na sociedade dominada pela indústria cultural é a substituição do pensamento pelo estereótipo da ação autônoma e refletida pela reprodução de clichês. Por sua vez, de acordo com Adorno e Horkheimer (1985; p. 130), a "condição de vida nesta sociedade é... o esmagamento de toda resistência individual". O inimigo dela é o "sujeito pensante", pois, a cultura industrializada, numa sociedade de massa, requer indivíduos submetidos a uma condição de levar uma "vida inexorável".

Ora, se pensarmos sobre a condição do sujeito na era da totalização social capitalista, percebe-se a condição insistente de liquidação da subjetividade e de qualquer forma de alteridade. Então, podemos pensar aqui a perda da capacidade reflexiva do sujeito jogado na lógica mercantil do sistema, que faz jus ao comportamento regressivo e muitas vezes, autodestrutivo.

\section{O mito de Ulisses e a dissolução da subjetividade: desdobramentos da massificação cultural globalizada}

Adorno e Horkheimer, na Dialética do Esclarecimento (1985), ao analisarem a proto-história mítica da razão ocidental, se depararam com a protohistória do sujeito moderno em busca do esclarecimento. Os autores buscaram erigir, diante da transformação da racionalidade humana, como unicamente razão instrumental, a condição da subjetividade e os desdobramentos do projeto do esclarecimento, nos vários aspectos de nossa sociedade e de nossa história.

Nesse sentido, podemos dizer que os autores avançaram suas análises a partir de uma pergunta central: Por que indivíduos, aparentemente esclarecidos e partícipes do processo civilizatório, se submetem a condições que contrariam seus próprios interesses? Em grande parte, essa pergunta acompanha nossa reflexão, sobretudo, para entender por que a razão se transforma em um instrumento a serviço da dominação.

O texto da Dialética do Esclarecimento mostra com particular crueza que, no processo da civilização ocidental, o sujeito moderno universaliza e sacraliza ao mesmo tempo, uma identidade contraditória. Com efeito, no âmago da própria individualidade burguesa, vislumbrava-se a manutenção do mito por meio de sua principal figuração do sujeito esclarecido. A tentativa de morte aos mitos e repressão ao medo foram às artimanhas da razão para a constituição e a adaptação do sujeito ao mundo.

Nesse aspecto, as figuras mitológicas, para os autores frankfurtianos aparecem como os arquétipos da ratio burguesa, abstrata e objetivante. 
Para sustentar essa tese, Adorno e Horkheimer procuram a "arqueologia psíquica do eu". Desse modo, os autores recorrem a Odisseia, de Homero, para situar a exemplar condição do sujeito a partir das transformações históricas do capitalismo. Nesse sentido, é emblemática a figura homérica de Ulisses, vista como o protótipo do indivíduo burguês esclarecido.

No excurso I chamado de Ulisses ou mito e esclarecimento, Adorno e Horkheimer retratam o drama que enreda a própria condição da subjetividade ocidental. Para esses autores, a grande aventura do sujeito começa com sua necessidade de garantir sua sobrevivência material, isto é, o seu objetivo mais imediato é submeter-se à "ditadura da autoconservação". Adorno e Horkheimer (1985, p. 61) assinalam ainda que:

O domínio do homem sobre si mesmo, em que se funda o seu ser, é sempre a destruição virtual do sujeito a serviço do qual ele ocorre; pois a substância dominada, oprimida e dissolvida pela autoconservação, nada mais é senão o ser vivo cujas funções configuram, elas tão somente, as atividades da autoconservação, por conseguinte exatamente aquilo que na verdade devia ser conservado.

Ulisses, tanto no episódio com as sereias, quanto com o ciclope Polifemo (para citar apenas dois dos confrontos da subjetividade emergente contra as potências da natureza presentes em Odisseia), é, fisicamente, inferior a eles, não podendo enfrentá-los de forma direta. Por isso, procura ser cauteloso, controla seus apetites instintivos e calcula friamente a hora em que pode quebrar o encanto (a força) das potências míticas, o que ele faz por meio da astúcia $^{3}$. Astúcia - que Adorno e Horkheimer (1985; p. 64) definem como "o desafio que se tornou racional" - é a arma da autoconservação mítica do sujeito burguês.

A figura de Ulisses consegue enganar o mito porque se submete a ele, acrescenta a astúcia como nova artimanha da racionalidade. A astúcia nasce pela aparente rendição do herói às leis mitológicas da natureza a fim de superá-la. Consiste na sua rendição aparente às normas da natureza, assimilando-a para poder, logo em seguida, negá-la.

\footnotetext{
${ }^{3}$ Um exemplo da relação astuciosa do herói Ulisses é seu encontro com o ciclope Polifemo (Canto IX). Para vencer o monstro de um olho só, que se alimenta de carne humana, Ulisses manipula o significado da palavra para poder modificar seu nome. Quando indagado pelo gigante sobre sua identidade, Ulisses (Odisseus) responde "Udeis" (ninguém), fazendo com que o ciclope se confunda, para que Ulisses possa escapar. Segundo os frankfurtianos "a astúcia da autoconservação vive do processo que rege a relação entre a palavra e a coisa". (ADORNO \& HORKHEIMER, 1985; p. 65).
} 
Como os heróis de todos os romances posteriores, Ulisses por assim dizer se perde a fim de se ganhar. Para alienar-se da natureza, ele se abandona à natureza, com a qual se mede em toda aventura, e, ironicamente, essa natureza inexorável que ele comanda triunfa quando ele volta - inexorável - para casa, como juiz e vingador do legado dos poderes de que escapou (ADORNO \& HORKHEIMER, 1985; p. 56).

Com base nessa ideia, podemos dizer que o medo do ser humano pelo desconhecido resulta na duplicação da natureza, mimetizando-a. O elemento comum assumido pelo sujeito, seja no estágio mágico ou no científico, é o logro da natureza. É nessa tentativa de duplicação que o sujeito procura afirmar-se e que torna possível tanto o mito quanto a ciência.

No entanto, para que a astúcia do herói triunfe, é necessário que ele dissimule sua rendição ao natural, numa relação mimética com o objeto. Para os frankfurtianos, o mimetismo compõe a conotação de autodefesa do sujeito, no confronto com a natureza desconhecida, para livrar-se do medo. Essa foi a forma apreendida pelo sujeito para fundamentar a construção da sua própria identidade. Entretanto, podemos dizer que ele foi absorvido pela própria astúcia.

Não apenas a alienação do sujeito, dominado nessa lógica, é paga com sua mutilação, mas, também, a coisificação do espírito é enfeitiçada pela massificação. Sendo que tal massificação se desdobra na progressiva "totalização capitalista em todas as esferas da vida, como também do prisma de apreensão da sociedade como socialização produzida em determinadas condições" (MAAR, 2004, p; 165).

Essa totalização alcança os mais recônditos espaços da subjetividade. Ela escraviza o sujeito, submete-o aos caprichos da indústria cultural globalizada e ratifica a lógica do aparelhamento econômico capitalista. "Aquilo que a filosofia transcendental exaltou na subjetividade criadora é o cativeiro do sujeito em si, oculto para ele mesmo" (ADORNO, 1995; p. 191).

Esse cativeiro subjetivo reproduz o cativeiro social. Ou seja, o sujeito aparece e some, é engolido pela massificação cultural. O ser humano deixa de ser sujeito livre e autônomo e torna-se produto, que vive de uma falsa liberdade. Desse modo, a luta pela sobrevivência tornou-se uma guerra de todos contra todos, em que não há vencedores nem vencidos, mas apenas liquidação do indivíduo.

O que se destaca em nossos dias é a dissolução da subjetividade pela permanente permissão ao assédio de agentes externos da cultura do entretenimento: excesso de som, de luzes, ou seja, a asfixia cultural. Na lógica da indústria cultural, o indivíduo é visto apenas como alguém que deve seguir certos padrões pré-instituídos: a vida como negócio, até o humor é pré-fabricado. 
Hoje as fisionomias produzidas sinteticamente pela cultura mostram que já se esqueceu do que é a vida humana. O indivíduo é induzido a pensar que, se quer alcançar a felicidade, é preciso seguir os padrões do mercado. A cultura é transformada em cultura mercantil. Por exemplo, o rádio, o cinema, ao transmitir um bem cultural, só o considera top pela vendagem que proporciona no mercado de produtos culturais disponíveis.

Uma análise dos limites da cultura implica reconhecer uma retomada da situação insatisfatória dos sujeitos no interior da complexificação das sociedades capitalistas atuais. Nesse sentido, queremos insistir na constatação da continuidade daquilo que caracteriza a integração total dos indivíduos. Sublinhando assim a continuidade da dominação da cultura hegemônica no plano da objetividade e da subjetividade.

\section{Conformação cultural e educação danificada}

Na exaltação dos avanços técnico-científicos, contraditoriamente, o que tem predominado atualmente é, cada vez mais, o domínio da massificação cultural. Isso significa reconhecer uma insistente instrumentalização dos indivíduos e de suas relações. E foi isso, conforme o diagnóstico dos frankfurtianos, que colocou sob suspeita o projeto moderno de emancipação mediante o avanço da ciência e da tecnologia.

Dessa forma, não seria prematuro concluir que a conformação cultural atual tem a ver com a crescente sofisticação técnico-científica da indústria do entretenimento e da cultura. E, com as novas formas de dominação cultural, a sujeição é deliberada pela construção social prejudicada, isto é, por uma educação danificada. ${ }^{4}$ Desse modo, uma questão que se coloca é: como constituir sujeitos com poder de resistência a essa sujeição?

Em Minima Moralia $(1993)^{5}$, quando Adorno retrata a condição da vida danificada, revela que o processo de produção material capitalista arrastou consigo, como um apêndice do próprio sistema, a subjetividade. Como afirma Adorno (1993; p. 7): “O olhar lançado à vida transformou-se em ideologia, que tenta nos iludir, escondendo o fato de que não há mais vida" e que esta ficou "sem autonomia e sem substância própria".

\footnotetext{
${ }^{4}$ Aqui se faz referência ao subtítulo da obra de Theodor W. Adorno: Mínima Moralia: reflexões a partir da vida danificada, escrita durante os anos 40 , cujo centro é a aproximação da filosofia e a vida em sua mais detalhada situação na fase do capitalismo mundial. Ver também o texto: RAMOS-DE-OLIVEIRA, N. Reflexões sobre a educação danificada. In: ZUIN, A.A.S. (Org.) A educação danificada - contribuições à teoria crítica da educação. Petrópolis e São Carlos: Vozes e Editora da UFSCAR, 1998.

${ }^{5}$ Para Duarte (1997; p. 145-6), o principal escopo da Minima Moralia: reflexões a partir da vida danificada é uma reaproximação entre filosofia e a mais crua imediatidade da vida prosaica na fase tardia do capitalismo mundial. Nessa obra o autor empreende, em forma de aforismos, um implacável acerto de contas com uma representativa tradição filosófica, protagonizada por Kant, Hegel, Marx, Nietzsche, Schopenhauer e Freud, entre outros.
} 
Adorno nos oferece um desafio incômodo e provocador: desvelar as máscaras sob as quais a sociedade toma a preocupação de encobrir a danificação da vida. É a partir disso que o autor insiste na denúncia da razão instrumental, na qual se confunde racionalidade dos meios técnicos com racionalidade da dominação. Os processos do desenvolvimento científico e tecnológico, obliterado na razão instrumental, têm levado a efeito a própria racionalização da educação.

Nesses termos, a Minima Moralia nos serve como metáfora do capitalismo monopolista, radicalizado nos monopólios da especulação do capital financeiro internacional. Na indústria cultural, que aumentou ainda mais seu poder, fazendo com que os sujeitos sejam apenas apêndices da maquinaria tecnológica e se tornem cada vez mais parecidos com ela. E no mundo do capital, fazendo com que a vida adquira um caráter pálido, prejudicado, ou, como afirma o próprio Adorno (1993; p. 7):

\begin{abstract}
Aquilo que a "vida" significava outrora para os filósofos passou a fazer parte da esfera privada e, mais tarde ainda, da esfera do mero consumo, que o processo de produção material arrasta consigo como um apêndice sem autonomia e sem substância própria. Quem quiser saber a verdade acerca da vida imediata tem que investigar sua configuração alienada, investigar os poderes objetivos que determinam a existência individual no mais recôndito dela.
\end{abstract}

Os argumentos adornianos convertem-se em algo que mostra a modelagem de uma subjetividade absorvida pela totalidade social capitalista. A configuração alienada que a vida assume contemporaneamente não fica distante da compreensão de que a dominação está enraizada nos recônditos espaços da vida cotidiana. Ocultando-se naquilo que parece ser dela, ou seja, tornando a ideologia vigente algo intrínseco do indivíduo.

Nesse mundo globalizado, a vida particular é submetida ao poder, assim como a consciência do indivíduo é submetida aos esquemas da indústria cultural. A forma esmagadora como a massificação cultural submete o sujeito é a denúncia do embrutecimento expressada até nas mais simples condutas das pessoas. Assim se estamos vivendo os descaminhos da formação humana, é necessário que as pretensões formativas da educação não corroborem com esse estado de coisas.

\title{
Considerações finais
}

A educação, numa configuração social danificada, tem sérias dificuldades em proporcionar autonomia e liberdade. 
[...] Está justificada a suspeita dos antigos críticos culturais, segundo a qual num mundo em que a educação é um privilégio e o aprisionamento da consciência impede de qualquer modo o acesso das massas à autêntica vivência das formações espirituais, não mais importam tanto os conteúdos ideológicos específicos quanto o fato de que simplesmente haja algo preenchendo o vácuo da consciência expropriada e desviando a atenção do manifesto segredo (ADORNO, 1994; p. 87, grifo nosso).

De acordo com Adorno, todo o avanço tecnológico e o desenvolvimento das reformas educacionais não são suficientes para eliminar as mazelas formativas. Tais mazelas não são aleatórias ou espontâneas, são fruto de uma lógica perversa que insiste em permanecer. Mas a que interesse tal situação responde? A que universo de relações sociais está vinculada a condução desse interesse?

Na tentativa de compreender essas indagações, podemos pensar que as formas atuais de massificação cultural se instauram onde se supõe nova cultura. Desse modo, é necessário compreender o papel da indústria cultural que se impõe com seus inúmeros mecanismos deformativos. O que possibilita as condições desfavoráveis em relação ao potencial de emancipação dos sujeitos por meio da educação.

A educação, ainda hoje, vive seu paradoxo. De um lado, pode manter o modelo de conformação cultural imposta pela ideologia dominante, como pode oferecer dispositivos de resistência crítica. Mesmo quando ofertada a todos, ela pode em algum momento possibilitar uma vivência formativa adequada para se superar a situação vigente. Entretanto, o difícil é perceber esse momento, sobretudo quando as pessoas estão submetidas à lógica do entretenimento, ou seja, ao esvaziamento da retenção crítica dos conteúdos da cultura.

É importante lembrar, também, que educar para a emancipação das pessoas não é apenas possibilitar escola para todos, mas compelir rumo a atender às exigências de tal emancipação. Desse modo, podemos dizer que as relações de saberes e das práticas pedagógicas se constituem ainda na disputa com os conteúdos da indústria cultural globalizada.

\section{Referências bibliográficas}

ADORNO, T. Educação e emancipação. Trad. W.L. Maar. Rio de Janeiro: Editora Paz e Terra, 1995. 
ADORNO, T. Capitalismo tardio ou sociedade industrial. In: COHN, G. (Org.). Theodor W. Adorno. Pp. 62-75. São Paulo: Editora Ática, 1994.

ADORNO, T. Minima moralia. Trad. L.E. Bicca. $2^{a}$ Edição. São Paulo: Editora Ática, 1993.

ADORNO, T. \& HORKHEIMER, M. Dialética do esclarecimento: fragmentos filosóficos. Rio de Janeiro: Jorge Zahar Editor, 1985.

MAAR, W.L. Educação, sujeição e crítica na perspectiva de Adorno. In: DALBOSCO, C. et al. Sobre filosofia e educação: subjetividade-intersubjetividade na fundamentação da práxis pedagógica. Passo Fundo: UPF, 2004.

MAAR, W.L. Adorno, semiformação e educação. Educação e sociedade, 83(24): 459-76, 2003.

DUARTE, R. Teoria crítica da indústria cultural. Belo Horizonte: UFMG, 2003.

DUARTE, R. Adornos - nove ensaios sobre o filósofo frankfurtiano: Belo Horizonte: UFMG, 1997.

FREITAG, B. A teoria crítica: ontem e hoje. $5^{\text {a }}$ Edição. São Paulo: Editora Brasiliense, 2004.

HERMANN, N. A indústria cultural. In: TIBURI, M. \& DUARTE, R. Seis leituras sobre a dialética do esclarecimento. Pp. 69-78. Ijuí: UNIJUÍ, 2009.

RAMOS-DE-OLIVEIRA, N. Reflexões sobre a educação danificada. In: ZUIN, A.A.S. (Org.). A educação danificada - contribuições à teoria crítica da educação. Petrópolis e São Carlos: Editora Vozes e Editora da UFSCAR, 1998.

SCHWEPPENHÄUSER, G. Observadores paradoxais, testemunhas imaginárias: reflexões sobre uma teoria contemporânea da cultura de massa. Kriterion, 100(Dezembro): 44-56, 1999.

ZUIN, A.A.S. Indústria cultural e educação: o novo canto da sereia. São Paulo: FAPESP e Autores Associados, 1999. 